\title{
Ovarian tumours associated with pregnancy: a five year retrospective study in a tertiary care hospital
}

\author{
Sunanda N.*, Akhila M.V. \\ Department of Obstetrics and Gynecology, Cheluvamba hospital, MMC \& RI, Irwin road, Mysore - 570001,
} Karnataka, India

Received: 27 September 2015

Revised: 10 October 2015

Accepted: 26 October 2015

\section{*Correspondence:}

Dr. Sunanda N,

E-mail: sunanda_n@rediffmail.com

Copyright: $\odot$ the author(s), publisher and licensee Medip Academy. This is an open-access article distributed under the terms of the Creative Commons Attribution Non-Commercial License, which permits unrestricted non-commercial use, distribution, and reproduction in any medium, provided the original work is properly cited.

\section{ABSTRACT}

Background: Pregnancy with ovarian tumors was reviewed over a 5 year period to determine the types of ovarian tumors associated with pregnancy in patients undergoing surgery and also the maternal and fetal outcome.

Methods: This retrospective study of 17 cases of ovarian tumors treated surgically during pregnancy and puerperium was carried out at a tertiary hospital between June 2009 and June 2014 to determine the incidence, clinico pathological features and outcome.

Results: The overall incidence of ovarian tumor in pregnant woman undergoing surgery was 1 in $1693(0.025 \%)$ deliveries. 52.87\% tumors were diagnosed in the first and second trimesters of pregnancy. Ten $(58.82 \%)$ presented as an emergency at different periods of gestation with torsion being the most common cause of surgery. Serous cyst adenoma (23.52\%) and dermoid tumor (17.64\%) were the most common types of ovarian tumors found in the study. The incidence of malignant tumors was one (5.88\%).Maternal outcome was uneventful in all patients. Abortion rate was $100 \%$ in first trimester. Outcome in second trimester is inconclusive as few patients were lost to follow-up. Patients diagnosed in third trimester had an uneventful fetal outcome.

Conclusions: Ovarian tumors are encountered with greater frequency, most being benign and self-resolving with malignancy occurring in a small minority of cases. Removal of persisting or enlarging ovarian masses as soon as possible is important to obtain a final histologic diagnosis and rule out malignancy.

Keywords: Histopathology, Ovarian tumors, Pregnancy, Surgery

\section{INTRODUCTION}

Ovarian tumours are infrequently encountered during pregnancy, but when they do occur can pose a real challenge in diagnosis and management. The recently reported incidence of ovarian masses during pregnancy ranges from 1 in 400 to 1 in 1312 live births. ${ }^{1}$ The majority of these masses are corpus luteum or other functional cysts that usually resolve by 16 weeks of gestation. ${ }^{2}$ Some adnexal masses persist and $1-8 \%$ of these masses represent malignant tumors. ${ }^{2}$ The main concerns affecting patient management include the risk of fetal wastage, the possibility of surgery-related complications or a delayed diagnosis of a possible lethal disease or malignancy. Therefore, it is sometimes problematic to make the decision to intervene surgically, even though it is related to the nature of the emergency, such as torsion or rupture, tumor size, potential risks of complications, possibility of malignancy, gestational age at the time of diagnosis, and maternal age. ${ }^{3}$

In this study, we retrospectively reviewed 17 patients with ovarian tumours who underwent surgical intervention during pregnancy over a period of 5 years, to 
assess the surgical effects and characteristics of ovarian tumours during pregnancy.

\section{METHODS}

This retrospective study of surgical management of ovarian tumours associated with pregnancy was carried out in the Department of Obstetrics and Gynecology, Cheluvamba hospital, allied with Mysore medical college and research institute, Mysore between June 2009 to June 2014. Cases that were treated surgically were only included in the study. There were 67, 745 deliveries and 17 women were operated upon for an ovarian tumor diagnosed in the antepartum, intrapartum or postpartum period. Information of the patients regarding their age, parity, clinical presentation, gestational age at diagnosis and surgery, Ultrasonography features, treatment, maternal and fetal outcome and the histopathology of the tumors were noted from the hospital charts, operating room register and record books.

\section{RESULTS}

The overall incidence of ovarian tumors needing surgical management during pregnancy and puerperium was 1 in $1693(0.025 \%)$ deliveries .The mean age of the patients was 23.47 years (range 18-29 years). The mean gravidity was (range 1-4) and mean parity was (0-3). $8(47.05 \%)$ women were primigravida. Of the 17 tumours, $2(11.7 \%)$ were diagnosed in the first trimester, $7(41.17 \%)$ in the second trimester, $5(29.41 \%)$ in the third trimester incidentally during emergency caesarean section. 3 $(17.64 \%)$ tumours were diagnosed during puerperium (Table I). The tumours were mostly diagnosed by clinical examination and/or by routine ultrasound examination.

Ten $(58.82 \%)$ presented as an emergency at different periods of gestation and underwent laparotomy. Eight tumours were found to have torsion of the pedicle ( 2 in first trimester, 4 in second trimester and 2 during puerperium) 2 ruptured and 4 had haemorrhage into the cyst.

Of the 2 cases presenting as emergency during first trimester, both aborted within one week of surgery. In the second trimester, out of the seven cases, two cases continued pregnancy up to term and delivered vaginally, the rest were lost to follow up. Cases operated in third trimester had uneventful fetal outcome. Maternal outcome was uneventful in all patients.

Histopathological study of the tumours revealed 4 cases with Serous cystadenofibroma $(23.52 \%), 3$ cases of Dermoid tumour(17.64\%) one involving a squamous cell carcinoma within the dermoid teratoma, one case each of mucinous cyst adenoma, hemorrhagic follicular cyst, theca lutein cyst and the rest showing features of torsion (Table II). The incidence of malignant tumors was one $(5.88 \%)$.

\section{DISCUSSION}

The finding of an adnexal mass during pregnancy has been reported to range from 1 in 25 to 1 in 8000 pregnancies. ${ }^{4-11}$ This large variation is due to differences in the definition of clinically significant masses. In our study, we chose to review only cases where the mass was $5 \mathrm{~cm}$ or greater in size. Although it is possible to have small malignant masses, previous studies have reported no malignancies during pregnancy in lesions less than 5 $\mathrm{cm}$ in largest diameter. ${ }^{12-15}$

Table 1: Period of gestation and mode of presentation of patients.

\begin{tabular}{|lllll|}
\hline $\begin{array}{l}\text { Trimester } \\
\text { of } \\
\text { gestation }\end{array}$ & $\begin{array}{l}\text { No } \\
\text { of } \\
\text { cases } \\
(\%)\end{array}$ & $\begin{array}{l}\text { Asympto- } \\
\text { matic } \\
(\%)\end{array}$ & $\begin{array}{l}\text { Acute } \\
\text { Presentation }\end{array}$ & $\begin{array}{l}\text { Post } \\
\text { operative } \\
\text { complications }\end{array}$ \\
\hline $\begin{array}{l}\text { First } \\
\text { Trimester }\end{array}$ & 2 & 0 & 2 & $\begin{array}{c}2 \\
\text { abortions }\end{array}$ \\
\hline $\begin{array}{l}\text { Second } \\
\text { Trimester }\end{array}$ & 7 & 3 & 4 & \\
\hline $\begin{array}{l}\text { Third } \\
\text { Trimester }\end{array}$ & 5 & 5 & & \\
\hline Puerperium & 3 & 1 & 2 & \\
\hline Total & 17 & & & \\
\hline
\end{tabular}

Table 2: Histopathologic study of tumours

\begin{tabular}{|lll|}
\hline Type & Number & Percentage \\
\hline $\begin{array}{l}\text { Serous } \\
\text { Cystadenoma }\end{array}$ & 4 & $23.52 \%$ \\
\hline Dermoid & 3 & $17.64 \%$ \\
\hline $\begin{array}{l}\text { Mucinous } \\
\text { cystadenoma }\end{array}$ & 1 & $5.9 \%$ \\
\hline Hemorrhagic cyst & 1 & $5.9 \%$ \\
\hline Theca Lutein cyst & 1 & $5.9 \%$ \\
\hline $\begin{array}{l}\text { SCC in Dermoid } \\
\text { cyst }\end{array}$ & 1 & $5.9 \%$ \\
\hline
\end{tabular}

The treatment of ovarian tumors in pregnancy is still challenging, because the treatment decision is often associated with unacceptable errors. ${ }^{16,17}$ Regarding conservative management, it is widely recommended because the majority of ovarian tumors in pregnant

women spontaneously disappear during follow-up and only a few tumors are persistent and need further surgical intervention. ${ }^{18}$ In 2005, Schmeler and colleagues tried to estimate whether delaying surgery affects the risk of adverse maternal and fetal outcomes in patients diagnosed with an adnexal mass during pregnancy. ${ }^{19}$ They concluded that close observation is a reasonable alternative to antepartum surgery in patients with an adnexal mass during pregnancy in selected cases. ${ }^{19}$ In addition, study by Katz et al of a high-risk group (teratoma during pregnancy) failed to identify an unfavourable prognosis with these tumors, because complications are extremely rare. ${ }^{20}$ Therefore, these 
tumors should be managed conservatively, if possible with routine ultrasonographic follow-up during pregnancy. ${ }^{20}$ However, it is also important to confirm resolution of the mass or to excise it to make a pathological diagnosis. This results in a great deal of controversy because it is hard to make a decision to select good candidates at appropriate times to undergo ovarian surgery in pregnant women.

When surgical resection of a suspicious adnexal mass is contemplated after the point of viability, the potential risk of an undiagnosed ovarian malignancy must be balanced by the potential for fetal morbidity and mortality. The optimal time for surgical intervention must be individualized after weighing a multitude of factors, such as the degree of suspicion for malignancy, the possibility of metastatic disease, and the gestational age of the pregnancy.

An acute abdomen, in particular, might be one of the most urgent situations, and may be accompanied with early fetal loss if ovarian torsion occurs during the first trimester16. In fact, the most frequently seen and serious complication of ovarian tumor during pregnancy is torsion as seen in our study with a rate of $47.05 \%$ which is well above the general reported torsion rate of adnexal masses during pregnancy being $10-15 \%$. The majority of cases (ovarian torsion during pregnancy) are seen between 8-16 weeks, at which point the uterus grows faster. $^{21}$ In our study, among the 8 cases of torsion, 2 occurred in first trimester and among the remaining six that occurred in second trimester, 3 occurred before 20 weeks. Chang and colleagues have researched the topic of ovarian torsion during pregnancy, and found that the majority of cases $(75 \%)$ occurred in the first trimester. ${ }^{22}$ In 2009, the same group studied 174 patients and showed that only $5.9 \%$ of ovarian torsions occurred after 20 weeks, suggesting a higher risk of ovarian torsion before 20 weeks gestational age. ${ }^{23}$ In addition, the highest risk of ovarian torsion exists between the 10 th and 17 th week of gestation $(60 \%))^{22}$ Therefore, women found to have persistent adnexal masses in pregnancy should be made aware of the risk for torsion and counselled on the signs and symptoms of this complication.

Regarding the histopathological types, nearly all studies have found that cystic teratoma is the most common tumor removed during pregnancy (up to $40-50 \%$ ), but there is no doubt that the corpus luteum of the pregnancy and simple cysts are still frequently seen in the pathological diagnosis of ovarian tumor during pregnancy, ranging from $11 \%$ to $41 \%$. $^{12-14}$

In our study, we found the most common tumours to be both cystic teratoma and serous cyst adenoma ovary, the others being of mucinous cyst adenoma, hemorrhagic follicular cyst, theca lutein cyst. We had only one case of malignancy with an incidence of $5.9 \%$. Fortunately, the available data seem to indicate that most of the adnexal masses requiring removal during pregnancy are benign.
Whitecar et al16 found 1532 published cases of adnexal mass in pregnancy and reported an overall malignancy rate $2.8 \%$ (range: $0 \%$ to $10 \%$ ). These reports only included masses that were surgically removed. Nevertheless, as $2 \%$ to $3 \%$ of masses removed during pregnancy are found to be malignant, surgery remains an option for treatment of adnexal masses.

The questions regarding how or when to treat those pregnant women with asymptomatic, nonsuspicious cystic ovarian masses, and who should be treated with surgical intervention for adnexal masses during pregnancy remain unanswered. Providing answers to these questions is no simple matter and there is substantial controversy if issues such as anaesthesia risk, fetal loss, fear of malignancy, and anxiety regarding over manipulation of the functional ovarian cysts (which often spontaneously disappear) are taken into consideration. ${ }^{24}$ We included 17 women in our study who underwent surgical management among which $2(11.7 \%)$ in the first trimester, $7(41.17 \%)$ in the second trimester, 5 $(29.41 \%)$ in the third trimester during caesarean section and $3(17.64 \%)$ tumours during puerperium. Both the cases operated in the first trimester ended up in pregnancy loss suggesting the risk associated with surgery in first trimester. Among the other 7 operated antenatally, outcome was uneventful. All newborns in this study were born essentially normal, suggesting that anaesthesia at the time of ovarian surgery does not affect the fetuses, although the development of the fetuses after birth was not really evaluated in this study. However, based on a review of the literature, ${ }^{25-29}$ there are no known teratogenic effects from the use of commonly administered anaesthetic agents at standard concentrations at any gestational age. ${ }^{30}$

Besides the teratogenic effects of anaesthesia, other fetal complications of ovarian surgery during pregnancy may include those related to the development of changes in fetal hemodynamics, leading to the common practice of fetal monitoring during surgery. Documentation of fetal wellbeing before and after the surgical procedure, including ovarian surgery, can be accomplished through a reassuring electronic fetal heart rate monitoring or biophysical profile. $^{31,32}$ By contrast, the need for intraoperative fetal heart rate monitoring is more controversial, because little is known about normal fetal physiological responses to maternal anaesthesia and surgical stress. ${ }^{30}$ The American College of Obstetricians and Gynecologists states that fetal heart rate monitoring during non obstetric surgery in pregnant women should be evaluated on an individual basis, and according to the physician's judgment. ${ }^{33}$ In our study, the fetal status was not monitored during ovarian surgery.

There are many important issues regarding the characteristics of the ovarian tumor during pregnancy. First, the frequency of occurrence of teratoma is common, and contributes to the high risk of a surgical emergency during pregnancy, secondary to torsion. This 
suggests the need for a routine adnexal evaluation prior to conception, and surgical intervention before conception should be considered. Second, functional cysts, including follicular cysts, simple cysts, or paraovarian or paratubal cysts are also common and are not always free of risk; there was one case of cyst complicated with acute abdomen during pregnancy in our study. Third, the risk of malignancy is low during pregnancy, as demonstrated by the fact that only two women in our study had malignant ovarian tumors. Fourth, tumor size is important. When the tumor is $>10 \mathrm{~cm}$, surgical intervention can be considered. However, surgery can be delayed for those tumors $<5 \mathrm{~cm}$. Nonetheless, if the tumor is between $5 \mathrm{~cm}$ and $10 \mathrm{~cm}$, it is difficult to make a recommendation, although the risk of torsion is especially high in tumors of this size. In terms of surgical methods for ovarian tumor during pregnancy, either laparotomy or laparoscopy is safe for the mother and fetus. In addition, there is no difference in outcome for women treated with general or regional anaesthesia.

\section{CONCLUSIONS}

Ovarian tumours are encountered with greater frequency, most being benign and self-resolving with malignancy occurring in a small minority of cases. Conservative management is best unless a woman is symptomatic. Best time to operate is second trimester. Removal of persisting or enlarging ovarian masses as soon as possible is important to obtain a final histological diagnosis and rule out malignancy.

\section{Funding: No funding sources}

Conflict of interest: None declared

Ethical approval: The study was approved by the Institutional Ethics Committee

\section{REFERENCES}

1. Balci O, Gezginc K, Karatayli R, Acar A, Celik C, Colakoglu MC. Management and outcomes of adnexal masses during pregnancy: a 6-year experience. J Obstet Gynaecol Res. 2008;34:524-8.

2. Schmeler. Adnexal Masses in Pregnancy. VOL. 105, NO. 5, PART 1, 2005.

3. F.-H. Koo. An 11-year experience with ovarian surgery during pregnancy. Journal of the Chinese Medical Association. 2013;76:453.

4. Nelson MJ, Cavalieri R, Graham D, Sanders RC. Cysts in pregnancy discovered by sonography. J Clin Ultrasound. 1986;14:509-12.

5. Creasman WT, Rutledge F, Smith JP. Carcinoma of the ovary associated with pregnancy. Obstet Gynecol. 1971;38:111-6.

6. Whitecar MP, Turner S, Higby MK. Adnexal masses in pregnancy: a review of 130 cases undergoing surgical management. Am J Obstet Gynecol. 1999; 181:19-24.

7. Sherard GB, Hodson CA, Williams HJ, Semer DA, Hadi HA, Tait DL. Adnexal masses and pregnancy: a 12-year experience. Am J Obstet Gynecol. 2003;189:358-63.

8. Bromley B, Benacerraf B. Adnexal masses during pregnancy: accuracy of sonographic diagnosis and outcome. J Ultrasound Med. 1997;16:447-54.

9. Novak ER, Lambrou CD, Woodruff JD. Ovarian tumors in pregnancy: an ovarian tumor registry review. Obstet Gynecol. 1975;46:401-6.

10. Mazze RI, Kallen B. Reproductive outcome after anesthesia and operation during pregnancy: a registry study of 5,405 cases. Am J Obstet Gynecol 1989;161:1178-85.

11. Agarwal N, Parul Kriplani A, Bhatla N, Gupta A. Management and outcome of pregnancies complicated with adnexal masses. Arch Gynecol Obstet. 2003;267:148 -52.

12. Hill LM, Connors-Beatty DJ, Nowak A, Tush B. The role of ultrasonography in the detection and management of adnexal masses during the second and third trimesters of pregnancy. Am J Obstet Gynecol. 1998;179:703-7.

13. Thornton JG, Wells M. Ovarian cysts in pregnancy: does ultrasound make traditional management inappropriate? Obstet Gynecol 1987;69:717-21.

14. Bernhard LM, Klebba PK, Gray DL, Mutch DG. Predictors of persistence of adnexal masses in pregnancy. Obstet Gynecol 1999;93:585-9.

15. Osmers R. Sonographic evaluation of ovarian masses and its therapeutical implications. Ultrasound Obstet Gynecol. 1996;8:217-22.

16. Wang PH, Cheng MH, Lee WL. The choice of tocolytic drugs for preterm labor-comparison of COX-2 inhibitor and magnesium sulfate. J Obstet Gynaecol Res. 2008;34:439 e 40.

17. Morice P, Uzan C, Uzan S. Cancer in pregnancy: a challenging conflict of interest. Lancet. 2012;379:495 e 6 .

18. Wang PH, Chang WH, Cheng MH, Horng HC. Management of adnexal masses during pregnancy. J Obstet Gynaecol. Res. 2009;35:597 e 8.

19. Schmeler KM, Mayo-Smith WW, Peipert JF, Weitzen S, Manuel MD, Gordinier ME. Adnexal masses in pregnancy: surgery compared with observation. Obstet Gynecol. 2005;105:1098 e 103.

20. Katz L, Levy A, Wiznitzer A, Aheiner E. Pregnancy outcome of patients with dermoid and other benign ovarian cysts. Arch Gynecol Obstet. 2010;281:811 e 5 .

21. Usui R, Minakami H, Kosuge S, Iwasaki R, Ohwada M, Sato I. A retrospective survey of clinical, pathologic and prognostic features of adnexal masses operated on during pregnancy. J Obstet Gynaecol. Res 2000;26:89 e 93.

22. Chang SD, Yen CF, Lo LM, Lee CL, Liang CC. Surgical intervention for maternal ovarian torsion in pregnancy. Taiwan J Obstet Gynecol. 2011;50:458 e 62.

23. Yen CF, Lin SL, Murk W, Wang CJ, Lee CL, Soong YK. Risk analysis of torsion and malignancy for 
adnexal masses during. Pregnancy. Fertil Steril. 2009;91:1895 e 902.

24. Chen P, Yeh CC, Lee FK, Teng SE, Chang WH, Wang KC. Squamous cell carcinoma occurring in the pelvic after total hysterectomy and bilateral salpingooophorectomy for an ovarian mature teratoma with malignant transformation. Taiwan J Obstet Gynecol 2012;51:446 e 8.

25. Mazze R, Kallen B. Reproductive outcome after anesthesia and operation during pregnancy: a registry study of 5405 cases. Am J Obstet Gynecol 1989; $161: 1178$ e 85.

26. Kuczkowski KM. A review of obstetric anesthesia in the new millennium: where we are and where is it heading? Curr Opin Obstet Gynecol. 2010;22:482 e 6.

27. Chohan L, Kilpatrick CC. Laparoscopy in pregnancy: a literature review. Clin Obstet Gynecol. 2009;52:557 e 69.

28. Reedy MB, Kallen B, Kuehl TJ. Laparoscopy during pregnancy: a study of five fetal outcome parameters with use of the Swedish health registry.Am J Obstet Gynecol. 1997;177:673 e 9.
29. Jackson H, Granger S, Price R, Rollins M, Earie D, Richardson W. Diagnosis and laparoscopic treatment of surgical diseases during pregnancy: an evidencebased review. Surg Endosc. 2008;22:1917 e 27.

30. Kizer NT, Powell MA. Surgery in the pregnant patient. Clin Obstet Gynecol 2011;54:633e41.

31. ACOG Practice Bulletin 106, July 2009. Intrapartum fetal monitoring:nomenclature, interpretation, and general management principles. Obstet Gynecol 2009; $114: 192$ e 202.

32. ACOG Practice Bulletin 9, October 1999. Antepartum fetal surveillance.Int J Gynaecol Obstet 2000;68:175 e 85 .

33. ACOG Committee on Obstetric Practice. ACOG Committee Opinion 474, February 2011: nonobstetric surgery during pregnancy. Obstet Gynecol. 2011;117:420 e 1 .

Cite this article as: Sunanda N, Akhila MV. Ovarian tumours associated with pregnancy: a five year retrospective study in a tertiary care hospital. Int $\mathbf{J}$ Reprod Contracept Obstet Gynecol 2015;4:1965-9. 